\title{
CS Research Suare \\ The effects of fluid therapy during the first 12 hours from septic shock onset in pediatric patients
}

Eunju $\mathrm{Ha}$

Asan Medical Center https://orcid.org/0000-0002-2866-3848

DaHyun Kim

Asan Medical Center Children's Hospital

SeongJong Park

Asan Medical Center Children's Hospital

Won Kyoung Jhang ( $\nabla$ wkjhang@amc.seoul.kr)

Research article

Keywords: sepsis, shock, resuscitation, fluid therapy, hypotension, critical illness, child

Posted Date: July 16th, 2020

DOI: https://doi.org/10.21203/rs.3.rs-41319/v1

License: (c) (1) This work is licensed under a Creative Commons Attribution 4.0 International License.

Read Full License 


\section{Abstract}

Background: Initial fluid therapy is the cornerstone of hemodynamic resuscitation in pediatric patients suffering from septic shock. This study aimed to evaluate the association between fluid therapy during the first 12 hours from septic shock onset and clinical outcomes in a pediatric cohort.

Method: This was a retrospective, observational study of consecutive pediatric patients with septic shock admitted to our multidisciplinary pediatric intensive care unit (PICU) between January 2012 and December 2019. Total fluid administration within the first 12 hours from septic shock onset, patient characteristics, and outcome measurements were collected from validated electronic medical records.

Results: A total of 144 cases were included with an overall 28 -day mortality rate of $20.1 \%$. Among the survivors, the proportion of fluid received within the first 3 hours (36.9 \% vs $25.4 \%, p=.004)$ and within the last 3 hours ( $18.9 \%$ vs $21.3 \%, p=.031)$ of the total amount administered over a 12 hour period from septic shock onset showed a significant difference compared with the non-survivors. The mortality rate was lower in the group receiving the highest proportion of the total administered fluid within the first 3 hours $(13.9 \%$ vs $26.4 \%, p=.048)$. Patients receiving the highest proportion of fluid in the last 3 hours had a significantly higher mortality rate $(29.6 \%$ vs $14.4 \%, p=.025)$. By multivariable logistic regression analysis, we also found that a higher proportion of administered fluid within the first and last 3 hours was associated with decreased mortality $(\mathrm{OR}, 0.951 ; 95 \% \mathrm{Cl}, 0.918-0.986 ; p=.028)$ and increased mortality (OR, $2.761 ; 95 \% \mathrm{Cl}, 1.175-6.495 ; p=.020)$, respectively.

Conclusions: An increased fluid intake within the first 3 hours of septic shock onset is associated with a decreased 28-day mortality. Moreover, a higher administration of fluids from 9 to 12 hours after this onset seems to be related to a poorer survival outcome. Treating pediatric septic shock cases with higher amounts of fluid within the first 3 hours of onset and then with more conservative levels thereafter may lead to better survival outcomes.

\section{Background}

Septic shock remains the leading cause of morbidity and mortality in children, with fatality rates of up to $60 \%$ [1]. In severe cases of sepsis and septic shock, the main therapeutic treatment approaches are intravenous fluids, appropriate antibiotics, source control, vasopressors, and ventilator support [2]. In 1991, Carcillo et al. reported that a decrease in mortality in pediatric septic shock cases was associated with higher volumes of initial fluid resuscitation [3]. In that study, the children who received a $40 \mathrm{ml} / \mathrm{kg}$ volume of resuscitation fluid or greater in the first hour from septic shock onset showed improved survival rates compared with cases that received smaller initial resuscitation fluid amounts. A growing body of evidence subsequently led to a consensus statement in 2002 for the hemodynamic support of pediatric and neonatal patients in septic shock [4]. These practice guidelines recommended aggressive fluid resuscitation that targets the normalization of vital signs and clinical evidence for perfusion in the first hour and then the subsequent titration of inotropes and vasopressors combined with ongoing 
volume resuscitation. These guidelines were updated in 2007 and again in 2017 without significant changes to the continued focus on early and aggressive normalization of perfusion, initially using an aggressive volume followed by the addition of vasopressors and inotropes [5]. In 2020, Surviving Sepsis Campaign (SSC) guidelines recommended a $40-60 \mathrm{ml} / \mathrm{kg}$ administration of bolus fluid over the first hour if hypotension was present but did not provide distinct recommendations regarding subsequent fluid therapy [6].

It is now recognized however that a positive fluid balance in the intensive care unit (ICU) is associated with an increased risk of mortality in adult septic shock. This has indicated that aggressive volume resuscitation is no longer advantageous in these cases, and may even be harmful in some patient populations [7-10]. Optimal fluid resuscitation is still recognized as a critical component of clinical interventions upon septic shock onset, and key to the initial stages of sepsis resuscitation but it is now believed that the appropriate timing and level of fluid resuscitation may be crucial for improving survival. Notably however, there have been few studies on the association of fluid balance and the timing of fluid resuscitation with patient outcomes in pediatric septic shock.

In our current study, we aimed to describe the characteristics of a cohort of children with septic shock and determine whether the amount and distribution of resuscitation fluid over the first 12 hours after onset are associated with mortality outcomes.

\section{Methods}

Pediatric septic shock cases were obtained through a review of the electronic patient records from January 2012 to December 2019 in a tertiary PICU of Asan Medical Center Children's Hospital, Seoul, Korea. We screened all consecutive admissions to identify patients under the age of 18 who diagnosed with septic shock requiring vasoactive agents. The diagnosis of septic shock was based on the 2017 guidelines of the American College of Critical Care Medicine committee [3,5]. We screened for patients who had 1) had a suspected infection manifested by hypothermia or hyperthermia, 2) had clinical signs of inadequate tissue perfusion that included any of the following: decreased or altered mental status, prolonged capillary refill greater than 2 seconds, diminished pulses, mottled cool extremities, flash capillary refill, bounding peripheral pulses and wide pulse pressure, or decreased urine output of less than $1 \mathrm{~mL} / \mathrm{kg} / \mathrm{hr}$, and 3) required inotropics or vasopressor to maintain an adequate perfusion or blood pressure. We excluded children who could not receive fluid resuscitation in accordance with the septic shock protocol due to severe pulmonary hypertension or increased intracerebral pressure, and any cases for whom detailed medical data were not available.

This study was approved by the Asan Medical Center Institutional Review Board. The requirement for informed consent was waived because of the retrospective and observational nature of the study. All patients were treated in accordance with our institution's pediatric septic shock management protocol.

\section{Data collection}


We retrospectively reviewed the electric medical records of enrolled patients and collected data on their baseline demographics, Pediatric Risk of Mortality (PRISM) score $\otimes$, need of mechanical ventilatory support, need for renal replacement therapy, length of ICU stay, 28 day mortality, and initial lactate level. The onset time of septic shock was defined as the point at which fluid resuscitation or vasoactive drugs were first administered to improve inadequate tissue perfusion. The total intake and output volumes were taken from the electronic medical records and used to calculate the fluid given for the first 3 hours and then in every subsequent 3 hour period during the first 12 hours from the onset of septic shock. The intake volume refers to all fluids administered and includes all nutritional fluid (or products), drugs, resuscitation bolus fluid and blood transfusions. The output volume was calculated from urine, dialysis, drainage, stools and vomitus.

The proportion of the final total 12 hour fluid volume that was administered in every 3 hour period was calculated and compared between the survivors and non-survivors. The higher proportion group in each 3 hour period was defined as the patients receiving a larger than median distribution of fluid, and the lower proportion group as those with a smaller than median distribution in that same period. The 28-day mortality rates between the higher and lower proportion groups in the each time period were compared.

\section{Statistical analysis}

Statistical analyses were conducted using SPSS, version 21.0 (IBM Corp, Armonk, NY). Categorical variables were reported as numbers and percentages and analyzed using the Fisher's exact test or chisquared test. Continuous variables were reported as medians (interquartile range, IQR). Two-tailed t-tests were used for normally distributed continuous variables, and the Mann-Whitney $U$ test was employed for non-parametric data. Multivariable logistic regression was used to estimate variables associated with the 28-day mortality rates. Variables were selected for inclusion in the multivariable models based on an a priori clinical rationale, and included age, gender, and the PRISM score $\Downarrow$. For all tests, a two-sided $p<0.05$ was considered statistically significant.

\section{Results}

Of the 167 children who initially met the inclusion criteria for this study, 23 were subsequently excluded. Fifteen patients did not have complete detailed data and the remaining eight cases were excluded as we could not challenge the fluid resuscitation due to severe pulmonary hypertension or increased intracerebral pressure. A total cohort of 144 children with septic shock was therefore enrolled. The characteristics of these cases and the results of the univariable analysis between the survivors and nonsurvivors are presented in Table 1. The median age and weight were 9.1 years and $20.6 \mathrm{~kg}$, respectively. The overall 28-day mortality in the total study population was $22.1 \%$. The most frequent underlying diseases were hemato-oncological disorders. However, the children in our current series with gastrointestinal diseases had the highest mortality rate of $33.3 \%$. There was significant difference in the PRISM $\nabla$ score on the day of onset between the survivors and non-survivors.

\section{Fluid balance and distribution over the first 12 hours}


As shown in Table 2, a similar amount of fluid was administered over the first 12 hours in both the survivors and non-survivors. However, when subgrouped into 3 hour periods post septic shock onset, survivors were given more fluids in the first 3 hours (21.9 vs $16.1 \mathrm{ml} / \mathrm{kg}, p=.239)$ and a significantly smaller amount of fluid in the last 3 hours compared to non-survivors $(9.4 \mathrm{vs} 13.1 \mathrm{ml} / \mathrm{kg}, p=014)$. There was no significant difference between survivors and non-survivors in the overall net fluid balance over the 12 hour period after septic shock. Figure 1 shows the distribution of administered fluid within every 3 hour period over these 12 hours. In the surviving children, the fluid administered in the first 3 hours accounted for the largest distribution with a gradual decline thereafter. In contrast, an even distribution of fluids over the 12 hours post septic shock was evident in the non-survivors.

\section{The relationship between the 28-day mortality and the distribution of fluid}

As shown in Fig. 2, when our subjects were divided into a higher and lower proportion group for the distribution of fluids in each 3 hour period, the higher proportion group for the first 3 hours showed a significantly lower 28-day mortality. Notably however, the higher proportion group in the last 3 hour period of the initial 12 hours after septic shock had a significantly higher 28-day mortality.

Table 3 presents the results of multivariable logistic regression analysis for possible risk factors for 28day mortality from septic shock, including the PRISM $\otimes$ score, higher proportion of fluid intake during the first 3 hours, and higher proportion group of fluid intake during 9-12 hours post septic shock. A higher proportion of fluid intake during the first 3 hours showed an association with a decreased 28-day mortality (OR, $0.951 ; 95 \% \mathrm{Cl}, 0.918-0.986 ; p=.028)$ and a higher proportion of fluid intake during $9-12$ hours was associated with an increased 28-day mortality (OR, 2.761; 95\% $\mathrm{Cl}, 1.175-6.495 ; p=.020)$.

\section{Discussion}

We aimed in our present study to evaluate whether fluid management within the first 12 hours from the onset of septic shock in children affected the clinical outcomes. Our results indicated that the total amount of fluid given within the first 12 hours was similar between the children who survived and those that did not with no difference in the net fluid balance between these two groups. What made the difference between the survivors and nonsurvivors was the distribution of the fluid administered within the first 12 hours. Survivors tended to be given about $40 \%$ of the total administered fluids over 12 hours in the first 3 hour period with a gradual decrease in volume thereafter. However, the non-survivors showed a much more even distribution of administered fluid over the first 12 hours after septic shock. Of particular note, the higher proportion fluid group for the first 3 hour period after septic shock onset had a significantly low 28-day mortality whereas the patients in the higher proportion group for the last 3 hour period (i.e. 9-12 hours post septic shock) showed the opposite result and had a significantly high 28-day mortality. 
The American College of Critical Care Medicine (ACCM) treatment guidelines for the first hour after the diagnosis of severe sepsis first and foremost recommend an aggressive fluid resuscitation of up to $60 \mathrm{~mL} / \mathrm{kg}$, followed by the titration of vasoactive medications based on the shock phenotype and, if necessary, additional fluids $[4,5,11]$. Even in the most recent SSC guidelines [6], the fluid therapy regimens have not changed. In practicality however, an aggressive resuscitation protocol of up to $60 \mathrm{~mL} / \mathrm{kg}$ within $60 \mathrm{~min}$ is not easy to administer and it is for this reason that there is insufficient time to assess the effects or adverse effects of fluid resuscitation in pediatric cases. Moreover, increasing consideration is now being given to the mounting evidence that a significant volume overload beyond the initial period of resuscitation may be harmful $[7,8,12]$. Fluid resuscitation is one of the essential components of septic shock treatment and it is obvious that early fluid resuscitation in the initial stages of septic shock is key to a successful outcome, as indicated in many prior reports [2-4, 13-15]. In our current study of a pediatric septic shock, the survival rate was higher in the children who received more fluid in the first 3 hours. This is a very important finding in terms of the future management of these cases to improve perfusion i.e. the microcirculation in the initial period of septic shock. However it is difficult to define the appropriate fluid volumes and the optimal hemodynamic targets in children. The important determinant of the fluid resuscitation approach would be the fluid responsiveness but this is very difficult to estimate and there is no consensus on the assessment tools for this purpose in pediatric patients [16-19].

In our current cohort, a smaller volume of resuscitation fluid was administered than is recommended the ACCM guidelines, i.e. an approximately $20 \mathrm{ml} / \mathrm{kg}$ volume within the first 3 hours. Notably however, the mortality rate among our study subjects was no higher than that reported in other studies. Although our institute follows the guidelines recommended by the ACCM or SSC, the fluid resuscitation approaches in septic shock are at the discretion of the treating physicians. These clinicians consider a number of factors that could affect the patient's fluid responsiveness, and the possible adverse effects of fluid resuscitation, including the impacts on cardiac function, respiratory function or renal function. Hence, the children in our current analysis did not receive the aggressive fluid resuscitation regimen recommended by the existing guidelines. Importantly, this did not seem to increase the mortality rate. This is another important observation from our present analysis and raises questions about whether the currently recommended aggressive fluid resuscitation approaches are essential within the first hour of septic shock onset. The goal of fluid resuscitation is to increase the mean circulating pressure and stroke volume, thereby improving the tissue perfusion pressure. However, the ability of crystalloids to expand the intravascular volume is poor and several prior studies have reported that less than $5 \%$ of a crystalloid bolus remains in the intravascular space at one hour after the end of the infusion [20, 21]. Macrocirculatory goals such as blood pressure or central venous pressure are currently recognized as poor indicators of microcirculation, especially in sepsis and septic shock [22]. Moreover, the microvasculature plays an independent role in tissue perfusion and oxygenation that may not be influenced by macrovascular alteration [23]. In relation to fluid bolus therapy, some animal studies using intra vital microscopy and video imaging of the microcirculation have shown both improvement as well as persistence in microcirculatory dysfunction with bolus therapy [24]. Thus, fluid therapy targeted at the 
macrocirculatory indicators can cause a fluid overload. The association of fluid overload and harm would be consistent in a broad spectrum of critically ill children. Most guidelines suggest an amount of fluid based on body weight and there is usually no accurate recommendation for fluid management after 1 hours. However, our present findings strongly indicate that basing the distribution of intake fluids over time on the patient's condition rather than body weight will have a far more beneficial impact on mortality outcomes in children with septic shock.

The recent Fluid Expansion as Supportive Therapy (FEAST) study, a Randomized Controlled Trial of fluid bolus therapy in over 3,000 acutely ill African children with sepsis and impaired perfusion, has been pivotal in generating interest in the potential harm from fluid resuscitation. The results of this trial indicated that both a higher early mortality $(<48 \mathrm{~h}$ ) and higher late mortality (4 weeks) among children who received fluid boluses in response to impaired perfusion compared to those who did not receive fluid bolus [9]. Interestingly, in the post hoc analysis of the FEAST study, fluid boluses were found to have provided short-term benefit in terms of resolution of shock state, but the children who received these fluid boluses had increased mortality due to progression of cardiovascular dysfunction after this initial improvement $[25,26]$.

Abulebda et al. have described how the volume balance may influence the clinical course in pediatric patients with septic shock during the period after ICU admission [27]. These authors stratified their analysis based on the risk of mortality using their risk stratification tool and reported that an increased fluid intake and positive fluid balance after ICU admission are associated with poorer outcomes in pediatric septic patients with a low initial mortality risk, but not in patients with a moderate or high mortality risk. Their results deviate somewhat from what others have described in adults with septic shock $[7,8,28-30]$ and show confounding outcomes according to the mortality risk. The reason for this limitation, as these authors pointed out, is the unavailability of data on the fluid balance of the subjects prior to their ICU admission. It is difficult to predict what the net effect on their results would have been if pre-ICU fluid balance data were available. On the other hand, a strength of our present study may be that the total intake fluid was estimated from the onset of shock regardless of the patient's location, i.e. whether they were in the emergency room or general ward. The effects of early fluid therapy have therefore been more clearly demonstrated in our current investigation.

The existing reviews in the literature have revealed that a positive fluid balance recognized at different times during the first 24 hours in the ICU, leading to a cumulative positive balance at discharge, is predictive of a higher mortality $[10,12,31-35]$. Of note in particular, Merik et al. have demonstrated that a low volume resuscitation below that recommended by the SSC guidelines on the first ICU day in septic shock cases was associated with the reduction in mortality [33]. It is noteworthy also that our present results, in a comparable manner to previous studies, have revealed that increases in the intake volumes from 3 hours after the onset of septic shock increases mortality. Importantly, we show from our current data that a high intake volume from 9 to 12 hours post-onset has a significant association with high mortality in children with septic shock. These findings indicate that an aggressive fluid resuscitation approach from 3 hours after septic shock onset may be harmful. 
Our study had several limitations of note. First, it was conducted in a single center and our results may therefore be lacking in general applicability. Second, our observational design incorporated a short period of only 12 hours, and we enrolled a smaller number of cases than other reports on fluid therapy. This limited our ability to determine a common relationship between fluid resuscitation and patient outcomes. Lastly, other factors such as antibiotic therapy, source control, and some other unmeasured clinical parameters may have contributed to our findings. For this reason, the prognosis of pediatric patients with septic shock cannot be explained simply by fluid therapy alone. It would thus appear difficult at present to standardize a single treatment protocol for these critically ill children or to draw clear conclusions from observational studies.

\section{Conclusions}

An increased fluid intake within the first 3 hours after septic shock onset in children is associated with a decreased 28-day mortality. Importantly however, an increased fluid intake after that time period seems to increase the mortality rate. Lower rates of mortality can thus be achieved in children diagnosed with septic shock who receive an adequate early fluid resuscitation regimen in the first 3 hours and conservative late fluid management from 3 to 12 hours after onset. We cautiously suggest therefore that a time-dependent fluid therapy strategy of 'positive early in the first 3 hours, negative late' will help to reduce morbidity and mortality in children with septic shock. However, because there is no current consensus on these strategies, high-quality tests in specific patient populations will be required in the future.

\section{Declarations}

\section{Acknowledgements}

Not applicable

\section{Authors' contribution}

WKJ, SJP designed the overall study. EJH and DHK carried out the collection and statistical analysis of the data. EJH drafted the manuscript. All authors contributed to the interpretation of the results and the revision of the final manuscript.

\section{Funding}

Not applicable

\section{Availability of data and materials}

The datasets used and/or analysed during the current study are available from the corresponding author on reasonable request. 
Ethics approval and consent to participate

Institutional review board of Asan Medical Center approved this study and waived the requirement for informed consent (study number: 2019-1269)

Consent for publication

Not applicable

\section{Competing interests}

The authors declare that they have no competing interests

\section{Author details}

${ }^{1}$ Pediatric Nursing Department, Asan Medical Center Children's Hospital, 88, Olympic-Ro 43-Gil, SongpaGu, Seoul 05505, Republic of Korea. ${ }^{2}$ Division of Pediatric Critical Care Medicine, Department of Pediatrics, Asan Medical Center Children's Hospital, University of Ulsan College of Medicine, 88, OlympicRo 43-Gil, Songpa-Gu, Seoul 05505, Republic of Korea.

\section{Abbreviations}

PICU: Pediatric Intensive Care U; SSC: Surviving Sepsis Campaign; PRISM score 『: Pediatric Risk of

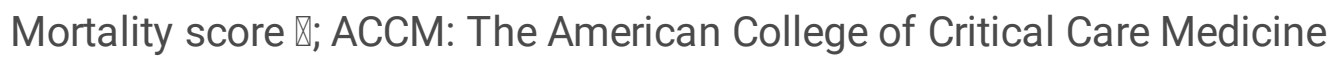

\section{References}

1. Menon K, McNally JD, Zimmerman JJ, Agus MS, O'Hearn K, Watson RS, Wong HR, Duffett M, Wypij D, Choong K: Primary Outcome Measures in Pediatric Septic Shock Trials: A Systematic Review. Pediatr Crit Care Med 2017, 18(3):e146-e154.

2. Goldstein B, Giroir B, Randolph A: International pediatric sepsis consensus conference: definitions for sepsis and organ dysfunction in pediatrics. Pediatr Crit Care Med 2005, 6(1):2-8.

3. Carcillo JA, Davis AL, Zaritsky A: Role of early fluid resuscitation in pediatric septic shock. Jama 1991, 266(9):1242-1245.

4. Carcillo JA, Fields Al: Clinical practice parameters for hemodynamic support of pediatric and neonatal patients in septic shock. Crit Care Med 2002, 30(6):1365-1378.

5. Davis AL, Carcillo JA, Aneja RK, Deymann AJ, Lin JC, Nguyen TC, Okhuysen-Cawley RS, Relvas MS, Rozenfeld RA, Skippen PW et al: American College of Critical Care Medicine Clinical Practice Parameters for Hemodynamic Support of Pediatric and Neonatal Septic Shock. Crit Care Med 2017, 45(6):1061-1093.

6. Weiss SL, Peters MJ, Alhazzani W, Agus MSD, Flori HR, Inwald DP, Nadel S, Schlapbach LJ, Tasker RC, Argent AC et al: Surviving Sepsis Campaign International Guidelines for the Management of 
Septic Shock and Sepsis-Associated Organ Dysfunction in Children. Pediatr Crit Care Med 2020, 21(2):e52-e106.

7. Alsous F, Khamiees M, DeGirolamo A, Amoateng-Adjepong Y, Manthous CA: Negative fluid balance predicts survival in patients with septic shock: a retrospective pilot study. Chest 2000, 117(6):17491754.

8. Boyd JH, Forbes J, Nakada TA, Walley KR, Russell JA: Fluid resuscitation in septic shock: a positive fluid balance and elevated central venous pressure are associated with increased mortality. Crit Care Med 2011, 39(2):259-265.

9. Maitland K, Kiguli S, Opoka RO, Engoru C, Olupot-Olupot P, Akech SO, Nyeko R, Mtove G, Reyburn H, Lang T et al: Mortality after fluid bolus in African children with severe infection. N Eng/ J Med 2011, 364(26):2483-2495.

10. Pittard MG, Huang SJ, McLean AS, Orde SR: Association of positive fluid balance and mortality in sepsis and septic shock in an Australian cohort. Anaesth Intensive Care 2017, 45(6):737-743.

11. Brierley J, Carcillo JA, Choong K, Cornell T, Decaen A, Deymann A, Doctor A, Davis A, Duff J, Dugas MA et al: Clinical practice parameters for hemodynamic support of pediatric and neonatal septic shock: 2007 update from the American College of Critical Care Medicine. Crit Care Med 2009, 37(2):666-688.

12. Vidal S, Perez A, Eulmesekian P: Fluid balance and length of mechanical ventilation in children admitted to a single Pediatric Intensive Care Unit. Arch Argent Pediatr 2016, 114(4):313-318.

13. Oliveira CF, Nogueira de Sa FR, Oliveira DS, Gottschald AF, Moura JD, Shibata AR, Troster EJ, Vaz FA, Carcillo JA: Time- and fluid-sensitive resuscitation for hemodynamic support of children in septic shock: barriers to the implementation of the American College of Critical Care Medicine/Pediatric Advanced Life Support Guidelines in a pediatric intensive care unit in a developing world. Pediatr Emerg Care 2008, 24(12):810-815.

14. Lee SJ, Ramar K, Park JG, Gajic O, Li G, Kashyap R: Increased fluid administration in the first three hours of sepsis resuscitation is associated with reduced mortality: a retrospective cohort study. Chest 2014, 146(4):908-915.

15. Simpson N, Lamontagne F, Shankar-Hari M: Septic shock resuscitation in the first hour. Curr Opin Crit Care 2017, 23(6):561-566.

16. Choi DY, Kwak HJ, Park HY, Kim YB, Choi CH, Lee JY: Respiratory variation in aortic blood flow velocity as a predictor of fluid responsiveness in children after repair of ventricular septal defect. Pediatric cardiology 2010, 31(8):1166-1170.

17. Gan H, Cannesson M, Chandler JR, Ansermino JM: Predicting fluid responsiveness in children: a systematic review. Anesthesia and analgesia 2013, 117(6):1380-1392.

18. Saxena R, Durward A, Steeley S, Murdoch IA, Tibby SM: Predicting fluid responsiveness in $\mathbf{1 0 0}$ critically ill children: the effect of baseline contractility. Intensive Care Med 2015, 41(12):2161-2169.

19. Desgranges FP, Desebbe O, Pereira de Souza Neto E, Raphael D, Chassard D: Respiratory variation in aortic blood flow peak velocity to predict fluid responsiveness in mechanically ventilated children: a 
systematic review and meta-analysis. Paediatric anaesthesia 2016, 26(1):37-47.

20. Sanchez M, Jimenez-Lendinez M, Cidoncha M, Asensio MJ, Herrerot E, Collado A, Santacruz M: Comparison of fluid compartments and fluid responsiveness in septic and non-septic patients. Anaesth Intensive Care 2011, 39(6):1022-1029.

21. Bark BP, Oberg CM, Grande PO: Plasma volume expansion by $0.9 \% \mathrm{NaCl}$ during sepsis/systemic inflammatory response syndrome, after hemorrhage, and during a normal state. Shock 2013, 40(1):59-64.

22. Timsit JF, Citerio G, Bakker J, Bassetti M, Benoit D, Cecconi M, Curtis JR, Hernandez G, Herridge M, Jaber S et al: Year in review in Intensive Care Medicine 2013: III. Sepsis, infections, respiratory diseases, pediatrics. Intensive Care Med 2014, 40(4):471-483.

23. Boerma $E C$, Ince $C$ : The role of vasoactive agents in the resuscitation of microvascular perfusion and tissue oxygenation in critically ill patients. Intensive Care Med 2010, 36(12):2004-2018.

24. Obonyo NG, Fanning JP, Ng AS, Pimenta LP, Shekar K, Platts DG, Maitland K, Fraser JF: Effects of volume resuscitation on the microcirculation in animal models of lipopolysaccharide sepsis: a systematic review. Intensive care medicine experimental 2016, 4(1):38.

25. Maitland K, George EC, Evans JA, Kiguli S, Olupot-Olupot P, Akech SO, Opoka RO, Engoru C, Nyeko R, Mtove $\mathrm{G}$ et al: Exploring mechanisms of excess mortality with early fluid resuscitation: insights from the FEAST trial. BMC medicine 2013, 11:68.

26. Myburgh J, Finfer S: Causes of death after fluid bolus resuscitation: new insights from FEAST. BMC medicine 2013, 11:67.

27. Abulebda K, Cvijanovich NZ, Thomas NJ, Allen GL, Anas N, Bigham MT, Hall M, Freishtat RJ, Sen A, Meyer $\mathrm{K}$ et al: Post-ICU admission fluid balance and pediatric septic shock outcomes: a risk-stratified analysis. Crit Care Med 2014, 42(2):397-403.

28. Vincent JL, Sakr Y, Sprung CL, Ranieri VM, Reinhart K, Gerlach H, Moreno R, Carlet J, Le Gall JR, Payen D: Sepsis in European intensive care units: results of the SOAP study. Crit Care Med 2006, 34(2):344-353.

29. Smith SH, Perner A: Higher vs. lower fluid volume for septic shock: clinical characteristics and outcome in unselected patients in a prospective, multicenter cohort. Crit Care 2012, 16(3):R76.

30. Yealy DM, Kellum JA, Huang DT, Barnato AE, Weissfeld LA, Pike F, Terndrup T, Wang HE, Hou PC, LoVecchio $\mathrm{F}$ et al: A randomized trial of protocol-based care for early septic shock. $\mathrm{N}$ Engl J Med 2014, 370(18):1683-1693.

31. Brandt S, Regueira T, Bracht H, Porta F, Djafarzadeh S, Takala J, Gorrasi J, Borotto E, Krejci V, Hiltebrand LB et al: Effect of fluid resuscitation on mortality and organ function in experimental sepsis models. Crit Care 2009, 13(6):R186.

32. Rehberg S, Yamamoto Y, Sousse L, Bartha E, Jonkam C, Hasselbach AK, Traber LD, Cox RA, Westphal $\mathrm{M}$, Enkhbaatar $\mathrm{P}$ et al: Selective V(1a) agonism attenuates vascular dysfunction and fluid accumulation in ovine severe sepsis. Am J Physiol Heart Circ Physiol 2012, 303(10):H1245-1254. 
33. Marik PE, Linde-Zwirble WT, Bittner EA, Sahatjian J, Hansell D: Fluid administration in severe sepsis and septic shock, patterns and outcomes: an analysis of a large national database. Intensive Care Med 2017, 43(5):625-632.

34. Sakr Y, Rubatto Birri PN, Kotfis K, Nanchal R, Shah B, Kluge S, Schroeder ME, Marshall JC, Vincent JL: Higher Fluid Balance Increases the Risk of Death From Sepsis: Results From a Large International Audit. Crit Care Med 2017, 45(3):386-394.

35. Tigabu BM, Davari M, Kebriaeezadeh A, Mojtahedzadeh M: Fluid volume, fluid balance and patient outcome in severe sepsis and septic shock: A systematic review. J Crit Care 2018, 48:153-159.

\section{Tables}

Table 1.

Baseline characteristics of the enrolled pediatric patients with septic shock 


\begin{tabular}{|c|c|c|c|c|}
\hline Variables & $\begin{array}{c}\text { Total } \\
(\mathrm{n}=144)\end{array}$ & $\begin{array}{l}\text { Survivors } \\
(\mathrm{n}=115)\end{array}$ & $\begin{array}{l}\text { Non-survivors } \\
\quad(n=29)\end{array}$ & $P$-value \\
\hline Age, years & $9.1(1.6-14.3)$ & $9.8(1.6-14.4)$ & $4.1(1.6-13.9)$ & 0.222 \\
\hline Boys, n (\%) & $89(61.8)$ & $61(61.7)$ & $18(62.1)$ & 0.576 \\
\hline Bwt, Kg & $20.6(7.7-43.0)$ & $24.6(7.4-44.0)$ & $14.4(9.2-42.8)$ & 0.274 \\
\hline Underlying disease, n (\%) & & & & 0.323 \\
\hline Hemato-oncology & $61(42.4)$ & $47(40.9)$ & $14(48.3)$ & \\
\hline Neurology & $23(16.0)$ & $21(18.3)$ & $2(6.9)$ & \\
\hline Cardiology & $18(12.5)$ & $14(12.2)$ & $4(13.8)$ & \\
\hline Respiratory & $16(11.1)$ & $14(12.2)$ & $2(6.9)$ & \\
\hline Gastro-intestinal & $12(8.3)$ & $8(7.0)$ & $4(13.8)$ & \\
\hline Others & $14(9.7)$ & $11(9.6)$ & $3(10.3)$ & \\
\hline PRISM III score & $11.0(8.0-17.0)$ & $11.0(8.0-15.0)$ & $14.0(11.0-20.0)$ & 0.013 \\
\hline Micro-organism, n (\%) & & & & 0.138 \\
\hline Fungus & $10(6.9)$ & $6(5.3)$ & $4(13.8)$ & \\
\hline Gram positive & $36(39.6)$ & $31(38.6)$ & $5(44.8)$ & \\
\hline Gram negative & $57(25.0)$ & $44(27.2)$ & $13(17.2)$ & \\
\hline Mycoplasma & $1(0.7)$ & $1(0.9)$ & $0(0.0)$ & \\
\hline Unproven & $40(27.8)$ & $33(28.9)$ & $7(24.1)$ & \\
\hline Length of ICU stay, day & $10(5-22)$ & $9(5-22)$ & $11(3.5-23.5)$ & 0.891 \\
\hline $\mathrm{CRP}, \mathrm{mg} / \mathrm{dL}$ & $10.0(2.8-18.3)$ & $9.9(3.2-18.7)$ & $10.0(2.4-16.7)$ & 0.673 \\
\hline Lactic acid, mmol/L & $2.1(1.0-4.5)$ & $2.0(1.0-4.2)$ & $3.8(1.4-8.5)$ & 0.052 \\
\hline Mechanical ventilation, $\mathrm{n}(\%)$ & $79(54.9)$ & $53(46.1)$ & $26(89.7)$ & 0.000 \\
\hline CRRT, n (\%) & $29(20.1)$ & $14(12.2)$ & $15(51.7)$ & 0.000 \\
\hline ECMO, n (\%) & $7(4.9)$ & $2(1.7)$ & $5(17.2)$ & 0.004 \\
\hline
\end{tabular}

Values are expressed as numbers (\%) or medians (IQR) unless otherwise indicated.

PRISM III score, Pediatric Risk of Mortality III score CRP, C-reactive protein 
CRRT, continuous renal replacement therapy

ECMO, extra-corporeal membrane oxygenator

Table 2.

Fluid administration pattern from the onset of septic shock in the pediatric patients

\begin{tabular}{lcccc}
\hline \multicolumn{1}{c}{ Variables } & $\begin{array}{c}\text { Total } \\
(\mathrm{n}=144)\end{array}$ & $\begin{array}{c}\text { Survivors } \\
(\mathrm{n}=115)\end{array}$ & $\begin{array}{c}\text { Non-survivors } \\
(\mathrm{n}=29)\end{array}$ & $\begin{array}{c}P \text { - } \\
\text { value }\end{array}$ \\
\hline $\begin{array}{l}\text { Amount of fluid received } \\
\text { During the first 12 hours, }\end{array}$ & $56.5(40.8-$ & $54.7(39 .-79.4)$ & $57.3(43.0-$ & 0.357 \\
ml/kg & $79.6)$ & & $85.3)$ & \\
0-3 hours, ml/kg & $21.4(11.3-$ & $21.9(12.1-$ & $16.1(10.6-$ & 0.239 \\
& $30.7)$ & $31.5)$ & $30.5)$ & \\
3-6 hours, ml/kg & $12.0(7.4-17.9)$ & $12.0(7.2-16.4)$ & $12.0(9.9-21.6)$ & 0.163 \\
6-9 hours, ml/kg & $11.2(7.6-17.7)$ & $10.9(6.8$ & $13.9(9.7-17.7)$ & 0.189 \\
& & $-17.8)$ & & \\
9-12 hours, ml/kg & $10.1(6.6-15.0)$ & $9.4(6.0-14.4)$ & $13.1(9.6-17.7)$ & 0.014 \\
Net fluid balance & & & & \\
During the first 12 hours, & $20.9(4.9-41.5)$ & $20.7(4.4-39.1)$ & $23.9(6.3-53.2)$ & 0.404 \\
ml/kg & & & & \\
0-3 hours, ml/kg & $14.8(4.3-27.3)$ & $16.7(4.8-27.7)$ & $12.4(3.6-23.0)$ & 0.199 \\
3-6 hours, ml/kg & $4.0(-2.9-10.0)$ & $3.1(-4.7-10.0)$ & $4.9(0.8-11.1)$ & 0.044 \\
6-9 hours, ml/kg & $3.0(-2.2-9.3)$ & $3.1(-2.8-9.4)$ & $2.8(-0.2-9.5)$ & 0.363 \\
9-12 hours, ml/kg & $1.4(-3.1-7.3)$ & $0.8(-3.6-6.5)$ & $3.1(-1.7-11.8)$ & 0.156 \\
\hline
\end{tabular}

Values are expressed as a median (IQR) unless otherwise indicated. 
Table 3.

Multivariable logistic regression analysis of 28-day mortality risk factors in the pediatric patients with septic shock

\begin{tabular}{lccc}
\hline \multicolumn{1}{c}{ Variables } & $\begin{array}{c}\text { Odds } \\
\text { Ratio }\end{array}$ & $\begin{array}{c}\text { 95\% Confidence } \\
\text { Interval }\end{array}$ & $P$-value \\
\hline PRISM III score & 1.069 & $1.012-1.130$ & .017 \\
$\begin{array}{l}\text { Higher proportion fluid intake group } \\
\quad \text { during the first 3 hours }\end{array}$ & 0.951 & $0.918-0.986$ & .028 \\
$\begin{array}{l}\text { Higher proportion fluid intake group during } \\
\text { 9-12 hours }\end{array}$ & & & \\
\hline
\end{tabular}

PRISM III score, Pediatric Risk of Mortality III score

Figures 


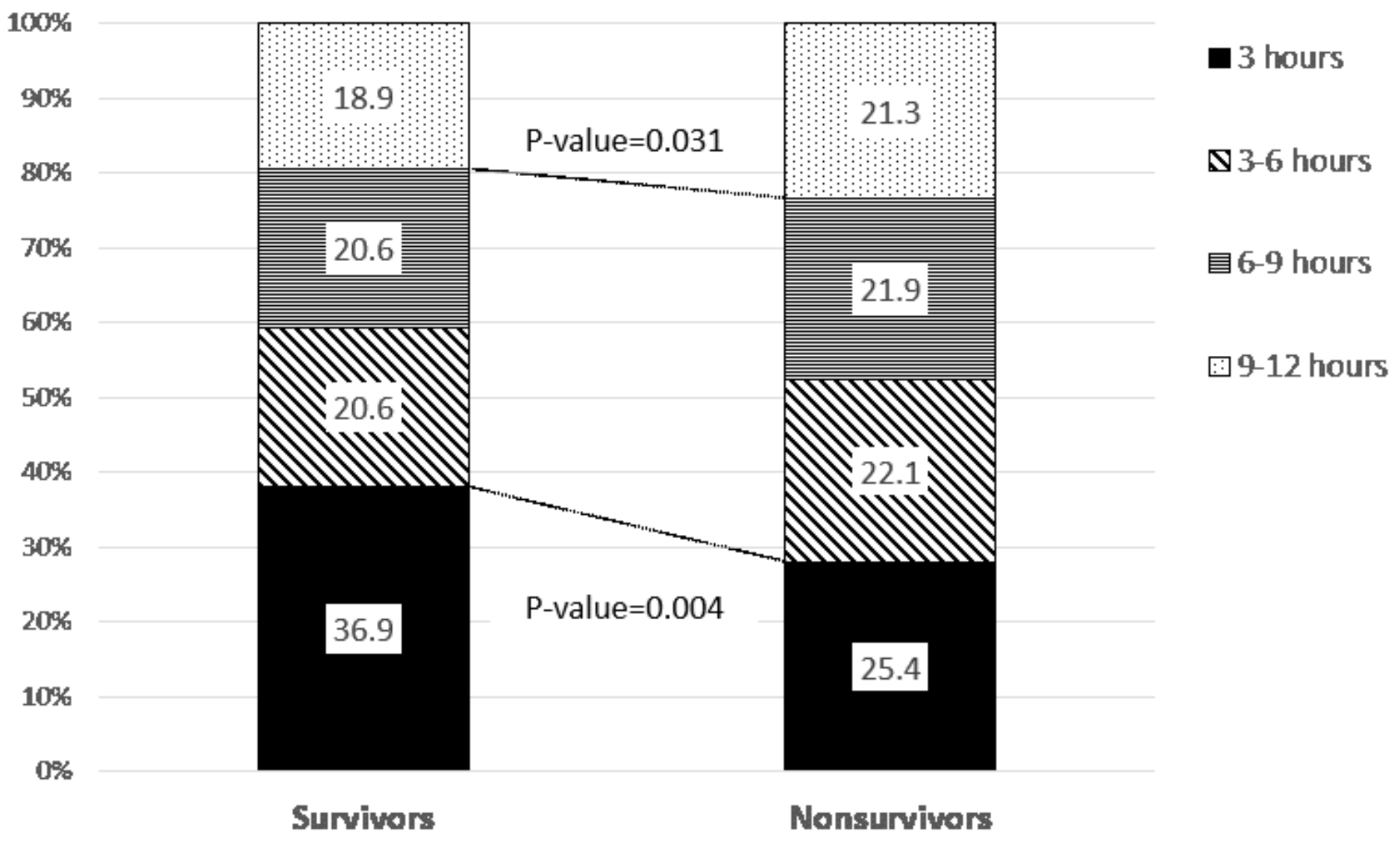

Figure 1

Distribution of the fluid administrated to the study patients during the 12 hour period from the onset of septic shock 
Mortality(\%)

35

$p$-value $=0.025$

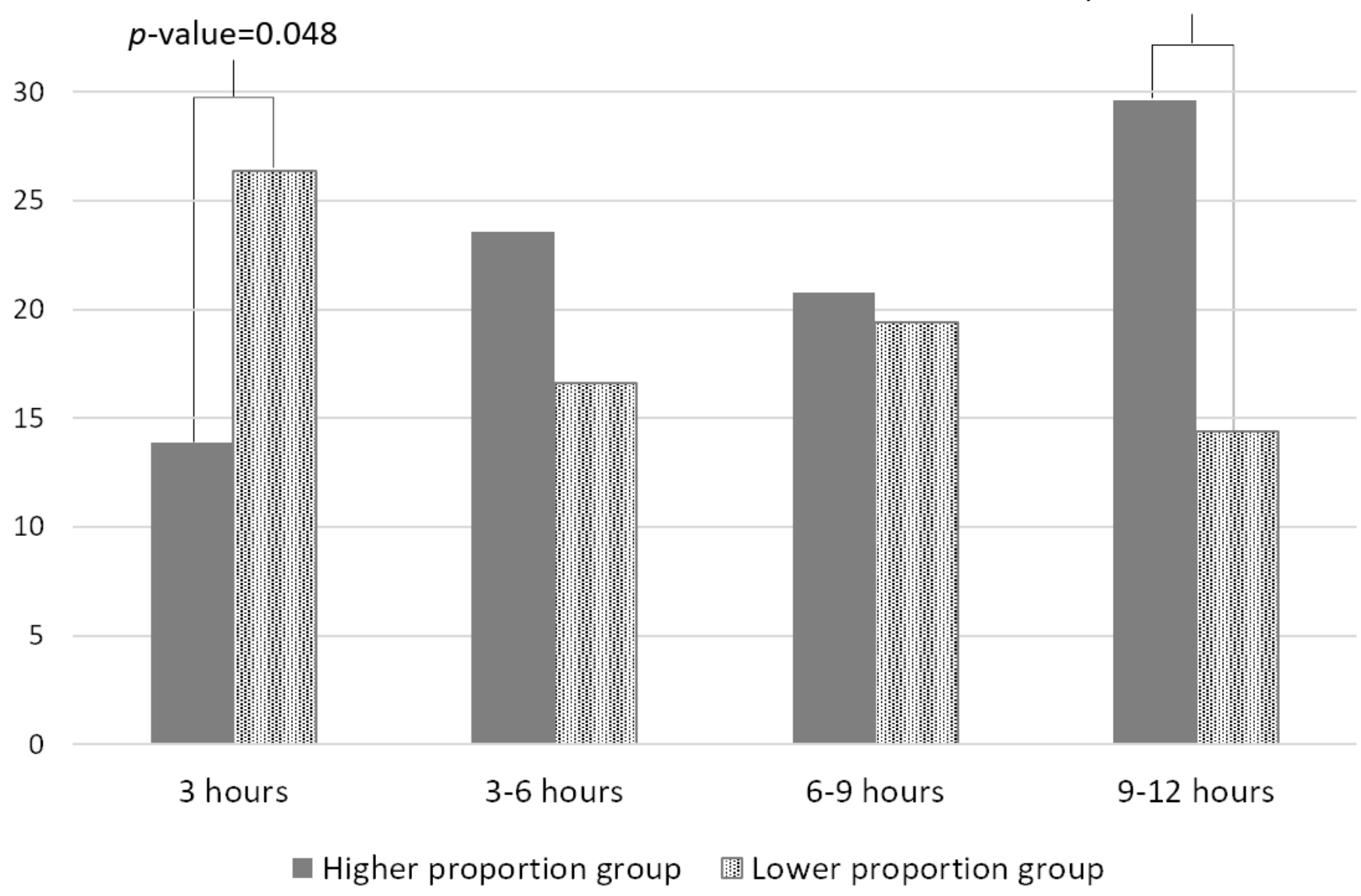

Figure 2

Comparison of mortality outcomes between the higher and lower fluid proportion groups stratified by the time from septic shock onset Higher proportion group, patients receiving a higher than median distribution of fluid within a discrete 3 hour period during the first 12 hours post septic shock Lower proportion group, patients receiving a lower than median distribution of fluid within a discrete 3 hour period during the first 12 hours post septic shock 